\title{
What Radiologists Should Know About Normal Pressure Hydrocephalus
}

\section{Was der Radiologe über den Normaldruckhydrozephalus wissen muss}

Authors

Till Illies ${ }^{1}$, Bernd Eckert ${ }^{1}$, Uwe Kehler ${ }^{2}$

Affiliations

1 Fachbereich Neuroradiologie, Asklepios Klinik Altona, Hamburg, Germany

2 Abt. f. Neurochirurgie, Asklepios Klinik Altona, Hamburg, Germany

Key words

normal pressure hydrocephalus, gait disorder, shunt, Alzheimer's, microangiopathy

received 31.08 .2020

accepted 15.02.2021

published online 2021

Bibliography

Fortschr Röntgenstr 2021; 193: 1197-1206

DOI 10.1055/a-1425-8065

ISSN 1438-9029

(C) 2021. Thieme. All rights reserved.

Georg Thieme Verlag KG, Rüdigerstraße 14,

70469 Stuttgart, Germany

Correspondence

PD Dr. Till Illies

Neuroradiology, AK Altona, Paul-Ehrlich-Straße 1,

22763 Hamburg, Germany

Tel.: $+49 / 40 / 1818818544$

t.illies@asklepios.com

\section{ABSTRACT}

Background Normal pressure hydrocephalus is a disease in elderly patients and one of the most common causes of treatable dementia. It occurs frequently with microangiopathy and Alzheimer's disease, so that differential diagnosis plays an important role. This is crucially determined by imaging findings. Therapy consists of cerebrospinal fluid drainage through a shunt, which should be performed as early as possible to improve the chances of success.

Method This report is based on a summary of the relevant literature that has been reviewed in PubMed with reference to epidemiology, symptoms, pathophysiology, diagnostics, and therapy. The results were supplemented by the joint guidelines of the German Society of Neurology and the German Society of Neurosurgery.

Results and Conclusion The understanding of the pathophysiologic changes leading to normal pressure hydrocephalus has expanded significantly in recent years to include concepts explaining relevant comorbidities. Diagnosis is based on radiological and clinical indicators, although accurate differentiation with respect to comorbidities is not always possible. A high response rate to treatment can be achieved by good patient selection. Positive prognostic markers for therapeutic success include Disproportionately Enlarged Subarachnoid Space Hydrocephalus (DESH), short disease duration, predominant gait disturbance, and few comorbidities.

\section{Key Points:}

- Normal pressure hydrocephalus mainly affects patients older than 65 years of age with high comorbidity rate for microangiopathy and Alzheimer's disease

- Radiologic findings play an important role in the diagnosis and follow-up after shunting

- The earlier a shunt is placed, the better the outcome

\section{Citation Format}

- Illies T, Eckert B, Kehler U. What Radiologists Should Know About Normal Pressure Hydrocephalus. Fortschr Röntgenstr 2021; 193: 1197-1206

\section{ZUSAMMENFASSUNG}

Hintergrund Der Normaldruckhydrozephalus ist eine Erkrankung älterer Patienten und eine der häufigsten Ursachen einer behandelbaren Demenz. Er tritt gehäuft mit einer Mikroangiopathie und einem M. Alzheimer auf, sodass die Differenzialdiagnostik eine wichtige Rolle spielt. Diese wird entscheidend von den Bildbefunden getragen. Die Therapie besteht in einer Liquorableitung durch einen Shunt, die möglichst frühzeitig erfolgen sollte, um die Erfolgsaussichten zu verbessern.

Methode Die Arbeit beruht auf einer Zusammenfassung der Literatur und wurde mittels Recherche in PubMed hinsichtlich der relevanten Arbeiten zu Epidemiologie, Klinik, Pathophysiologie, Diagnostik und Therapie durchgeführt. Ergänzt wurden die Resultate durch die gemeinsame Leitlinie der Deutschen Gesellschaft für Neurologie und der Deutschen Gesellschaft für Neurochirurgie.

Ergebnisse und Schlussfolgerung Das Verständnis der zu einem Normaldruckhydrozephalus führenden pathophysiologischen Veränderungen ist in den letzten Jahren deutlich er- 
weitert worden und schließt Konzepte zur Erklärung der Komorbiditäten mit ein. Die Diagnostik erfolgt anhand radiologischer und klinischer Indikatoren, wobei eine genaue Differenzierung zu den Komorbiditäten weiterhin nicht immer möglich ist. Durch gute Patientenselektion kann eine hohe
Ansprechrate auf die Therapie erreicht werden. Positive prognostische Marker für einen Therapieerfolg sind ein Disproportionally Enlarged Subarachnoid Space Hydrocephalus (DESH), eine kurze Krankheitsdauer, eine vorherrschende Gangstörung und wenige Komorbiditäten.

\section{Introduction}

Normal pressure hydrocephalus (NPH) is a chronic, non-occlusive hydrocephalus that frequently occurs in older patients. It is typically associated with gait disturbance, incontinence, and dementia, referred to as Hakim's triad [1, 2]. It is noteworthy that the cerebrospinal fluid pressure is not elevated. The cause of NPH was not clear for a long time. At present, a causal relationship with microangiopathy seems probable. There is speculation about a connection with Alzheimer's disease. The fact that NPH is often present at the same time as these diseases and that they are clinically similar can result in diagnostic and therapeutic difficulties. The treatment of choice is placement of a CSF shunt. With proper selection, this treatment achieves clinical improvement in the majority of patients. Nonetheless, treatment success if often partly determined by comorbidities. In addition, the shunt should be placed early in the course of the disease to increase the chance of success. These factors probably contributed to the fact that the acceptance of NPH was and in some cases still is low. This article provides an updated overview of the disease and a useful summary of important information for the daily routine. The focus is on the main aspects for radiologists since diagnostic imaging plays a central role and findings can often only be interpreted as part of the overall context.

\section{Clinical symptoms}

$\mathrm{NPH}$ is a disease in older patients and rarely occurs in people under the age of 65 years. It is difficult to provide more precise information regarding incidence due to the lack of standardization regarding diagnostic criteria. According to a Swedish study, the incidence is $0.2 \%$ among patients between 70 and 79 years old and $6 \%$ among patient over 80 years old. Men and women are affected with equal frequency $[3,4]$. Due to the chronic development of the disease, symptoms progress slowly and are typically not fully manifested. Therefore, it often takes a long time for patients to go see a physician. Gait disturbance is almost always the first symptom and the dominant symptom over the course of the disease. It can often initially only be perceived subjectively and is impossible or difficult to classify. In the advanced stage, the patient typically has a broad-based, shuffling gait. Headache as seen in acute hydrocephalus does not occur.

Although the dementia syndrome is not always clinically apparent, neuropsychological testing will show cognitive deficits in almost all patients. These deficits are characterized by subcortical frontal dementia with slowing of the psychomotor tempo and difficulty with verbal recall. Cortical functions, like speech, are not affected [5]. For differential diagnosis and prognosis determination, it is pro- blematic that mixed dementia is seen in many patients. It has a vascular origin in up to $60 \%$ of cases, typically microangiopathy, or more rarely embolic infarcts. In addition, beta-amyloid deposits as typically seen in Alzheimer's disease are found in up to $75 \%$ of cases [6]. However, the significance of these deposits without a corresponding clinical presentation has not been definitively clarified.

The frequency of urinary incontinence is $45-90 \%$ [7]. It is the result of an initially predominant autonomic dysfunction compounded by frontal lobe deficits presenting later in the disease course. Stool incontinence can occur in severe cases and is rare without simultaneous urinary incontinence [8-10].

\section{Pathophysiology}

NPH cannot be explained by a disruption in CSF production, impaired flow through the ventricles, or an absorption disorder in terms of the "bulk flow concept". According to the currently favored theory, NPH is the result of the so-called "water hammer" effect. The contents of the skull (brain parenchyma, CSF, and blood) have a constant volume so that volume changes in one compartment have to be compensated by changes in the others. The arterial blood volume depends on the cardiac cycle and increases during systole. This increase in volume is accounted for by a windkessel effect in the arteries. The compliance of the brain parenchyma and displacement of CSF and venous blood maintain a constant intracranial volume in a compensatory manner. In the case of NPH, the compliance particularly of the (perforating) arteries is reduced by lipohyalinosis and the compliance of the brain parenchyma is decreased by microangiopathic changes. This results in intracranial transmission of the arterial pulse so that there is a pulsatile increase in CSF pressure which is seen as an increased amplitude in CSF pressure measurements. The volume changes in CSF and venous blood no longer seem to be sufficient to compensate for this "water hammer" effect. This creates a pressure gradient between the ventricles and arachnoid spaces (transmantle pressure), resulting in enlargement of the lateral ventricles and lifting of the brain. This theory also explains the simultaneous presence of microangiopathy and $\mathrm{NPH}$.

According to a further theory, NPH is associated with the glymphatic system, which is responsible for removing cell degradation products from the brain. The function of this system is limited in both NPH and Alzheimer's patients. It is hypothesized that betaamyloid plaques can limit the function of the glymphatic system resulting in NPH and that limited function of the glymphatic system can promote plaque buildup resulting in Alzheimer's dementia $[11,12]$. 
- Table 1 Typical imaging findings in NPH.

\begin{tabular}{|c|c|c|}
\hline structure & finding & differential diagnosis/comment \\
\hline lateral ventricles & enlarged & $\begin{array}{l}\text { DD: brain volume reduction, } \\
\text { DD: occlusive hydrocephalus }\end{array}$ \\
\hline temporal horns & enlarged proportionately & $\begin{array}{l}\text { DD: hippocampal sclerosis } \\
\text { DD: atrophy in Alzheimer's disease }\end{array}$ \\
\hline third ventricle & enlarged & $\begin{array}{l}\text { lowering of the floor + } \\
\text { forward protrusion of the lamina terminalis } \\
\text { = pressure gradient DD: occlusion, DD: infratentorial } \\
\text { intracisternal obstructive hydrocephalus }\end{array}$ \\
\hline aqueduct & normal & $\begin{array}{l}\text { DD: aqueduct stenosis } \\
\text { DD: space-occupying lesion } \\
\text { Flow void in } T 2 \text { sagittal? T1w sagittal if applicable }\end{array}$ \\
\hline fourth ventricle & rarely enlarged & DD: occlusive hydrocephalus \\
\hline corpus callosal angle & $<90^{\circ}$ & $\begin{array}{l}\text { measured in the paracoronal plane at the level of the } \\
\text { posterior commissure ( } \vee \text { Fig. } 2 \text { ) }\end{array}$ \\
\hline $\begin{array}{l}\text { DESH } \\
\text { (disproportionately enlarged subarach- } \\
\text { noid space Hydrocephalus) }\end{array}$ & $\begin{array}{l}\text { widening of the sylvian fissure } \\
\text { narrowing of the arachnoid spaces at } \\
\text { the convexity }\end{array}$ & specific finding \\
\hline $\begin{array}{l}\text { extensive periventricular white matter } \\
\text { changes }\end{array}$ & $\begin{array}{l}\text { typical association of microangiopathy } \\
\text { and } \mathrm{NPH}\end{array}$ & $\begin{array}{l}\text { broad spectrum of DDs, e. g. } \\
\text { CSF diapedesis in acute hydrocephalus } \\
\text { multiple sclerosis } \\
\text { leukodystrophies }\end{array}$ \\
\hline
\end{tabular}

\section{Imaging/Diagnostic Workup}

Imaging plays a central role in the diagnosis of NPH following the patient interview and clinical examination. It is used here to provide evidence of the (typical) imaging findings of NPH and to rule out alternative causes, such as tumors, infarcts, or other forms of dementia. Imaging is then subsequently used for follow-up and detection of complications. In general, CT can be used for imaging. However, MRI should be given preference for the primary diagnostic workup due to its higher sensitivity and radiation hygiene considerations. After surgery, CT should be given preference because it provides better visualization of the shunt. The typical imaging features of NPH are discussed in the following [13-15] ( Table 1).

\section{Ventricular enlargement}

A primary sign of NPH is enlargement of the ventricular system ( $\triangleright$ Fig. 1). If present, NPH cannot be ruled out. This enlargement can be best identified based on the rounded frontal horns, enlarged trigone, and widened temporal horns. Enlargement of the temporal horns is a sensitive indicator of an increase in CSF pressure but must be differentiated from ex vacuo enlargement as seen in hippocampal sclerosis and atrophy of the mesial temporal lobe structures, e. g., in Alzheimer's dementia (see differential diagnoses). Paracoronal T2-weighted sequences angled toward the hippocampus are suitable for this because the key structures of the mesial temporal lobe can be evaluated ( $\vee$ Fig. 2, 6, 7).

The Evans Index, i. e., the maximum width of the anterior horns divided by the maximum internal diameter of the skull, is often ci- ted as a measurement of ventricular enlargement. However, the index is subject to significant variability due to the slice angulation, and it is less sensitive for the prediction of NPH and treatment response. Therefore, it does not seem useful here. Volumetry of the ventricles is more accurate but is also not suitable for the clinical routine due to the high time requirement [16, 17].

The third and fourth ventricles can also be enlarged in the case of NPH. Sagittal thin-slice T2 sequences with a long TR time are helpful for evaluating the third ventricle. Lowering of the floor of the third ventricle and bulging of the lamina terminalis can be interpreted here as an indication of a pressure gradient as seen in hydrocephalus with occlusion or stenosis. The flow voids visible in these sequences are also to be considered diagnostic (refer to "CSF flow visualization") ( $\triangleright$ Fig. 4, 5). Enlargement of the fourth ventricle is rather rare in NPH and can be an indication of an occlusion in a further distal location [18].

\section{Disproportionately enlarged subarachnoid space hydrocephalus (DESH)}

DESH is the most reliable radiological sign of NPH. In NPH, enlargement of the ventricular system results in lifting of the brain with the characteristic tight convexity sign and increased visibility of the arachnoid spaces in the basal segments, especially in the sylvian fissure. This differentiates NPH from occlusive hydrocephalus in which there is decreased visibility of all arachnoid spaces. DESH has a high positive predictive value for the success of shunt placement (77\%). A negative DESH does not rule out NPH (negative predictive value of $25 \%$ ) [19] ( $\$$ Fig. 1). After shunt placement, there can be improvement regarding the reduced visibility of the 


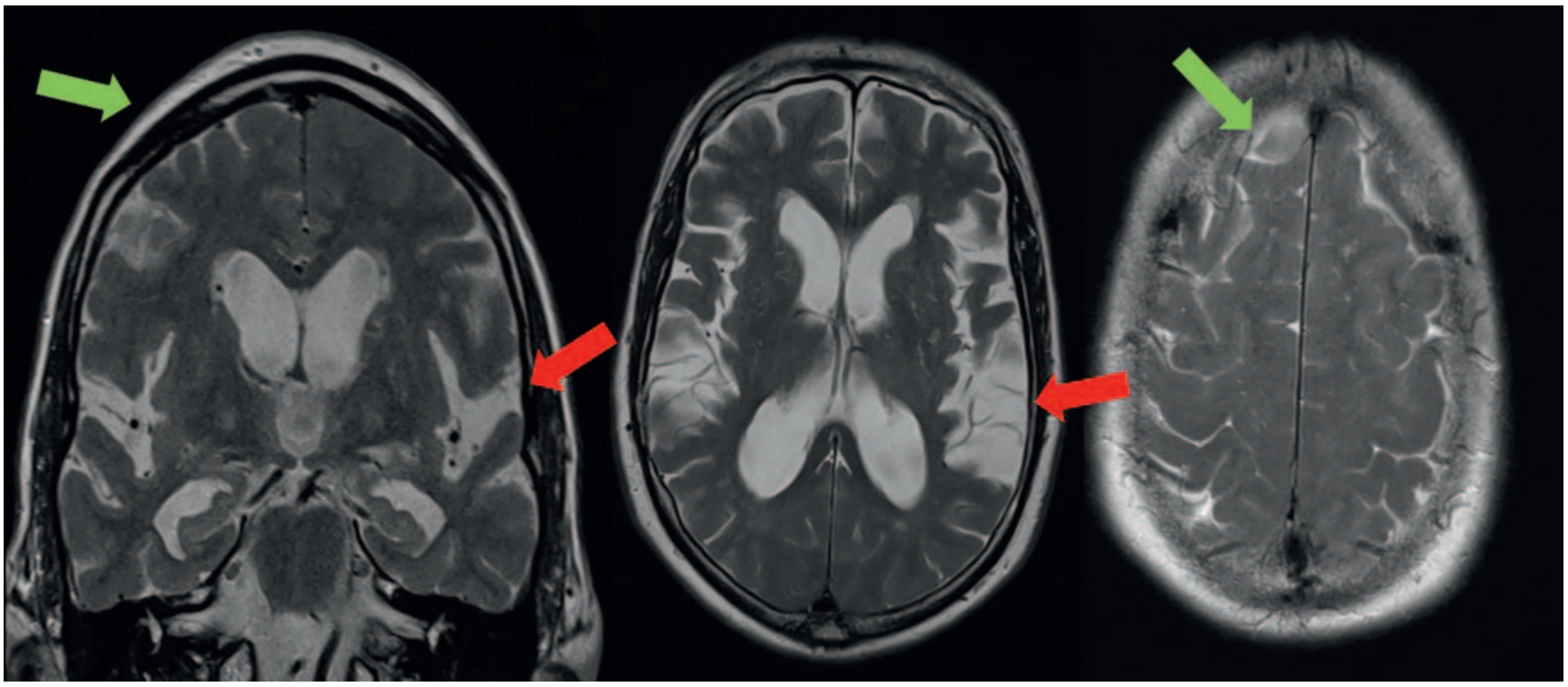

- Fig. 1 Coronal and transverse T2 sequences of patient with NPH show the typical finding of dilation of the ventricular system and the sylvian fissure (red arrow), while there is narrowing of the cortical arachnoid spaces at the vertex (green arrow).

arachnoid spaces. However, this improvement is not a prerequisite for clinical response.

\section{Corpus callosal angle (CC angle)}

The CC angle is closely connected to DESH where the CC angle becomes smaller and the arachnoid spaces are constricted as a result of the enlargement of the lateral ventricles in the convexity with a fixed corpus callosum. It is important to perform the measurement on paracoronal images acquired at the level of the posterior commissure (PC) perpendicular to the AC-PC line. A CC angle of less than $90^{\circ}$ indicates NPH and correlates with the success of shunt placement. It can normalize after the procedure. A small angle of up to $60^{\circ}$ further increases the specificity. However, there are no larger studies making it possible to determine the optimal cut-off $[20,21]$ ( Fig. 2).

\section{Leukoaraiosis}

Above-average changes can be seen in NPH patients. This can be explained by the high comorbidity of NPH and microangiopathy. Therefore, a lack of white matter changes makes NPH unlikely. Patients with pronounced white matter changes also benefit from shunt placement. However, it is not clear whether treatment success is reduced by microangiopathy. Although minor transependymal CSF absorption is postulated, it cannot be differentiated from microangiopathy. In addition, improvement regarding this finding is typically not seen after shunt placement $[11,22$, 23] ( Fig. 3).

\section{CSF flow visualization}

The flow voids seen on T2-weighted sequences with a long TR time can be used for qualitative visualization of CSF flow. However, the sequence that is used affects their comparability and diagnostic significance. Depending on the selected sequence and parameters, a flow void in the aqueduct can be normal or can indicate a stenosis. In some cases, the flow voids can be so significant that the aqueduct is no longer visible. T1-weighted images can be helpful here ( $\triangleright$ Fig. 4). Phase contrast encoding can be used to quantify CSF flow. Measurement of the stroke volume in the aqueduct is the most robust method. It is increased in NPH patients but cannot be used to reliably differentiate between $\mathrm{NPH}$ and non-NPH patients. The results of the studies are also inconsistent with respect to the prediction of the success of shunt placement. Therefore, flow quantification is not a reliable parameter but can be used as an additional element [24-29].

\section{Further diagnostic workup}

The spinal tap test is the most important clinical test for verifying $\mathrm{NPH}$. A large amount of CSF is removed (approx. 30-40 ml). Clinical tests, e. g., walking a certain distance while being timed, are used to evaluate the patient before and after the removal of CSF. Moreover, patients are asked to complete a questionnaire so that they can record their subjective assessment because questionnaires sometimes provide a better overview of improvements in symptoms than clinical tests. If the spinal tap test results in a temporary improvement, shunt treatment is indicated. It must be taken into consideration that the improvement can occur a few minutes up to two days after the removal of CSF and the duration of the improvement is highly variable. According to studies, the sensitivity of the test is $26-61 \%$. However, a negative spinal tap test does not rule out NPH. It is notable that a post-lumbar puncture syndrome is extremely rare in NPH patients.

\section{Differential diagnoses and comorbidities}

The differential diagnosis of NPH includes a broad spectrum of diseases with similar symptoms and imaging findings. Most of 


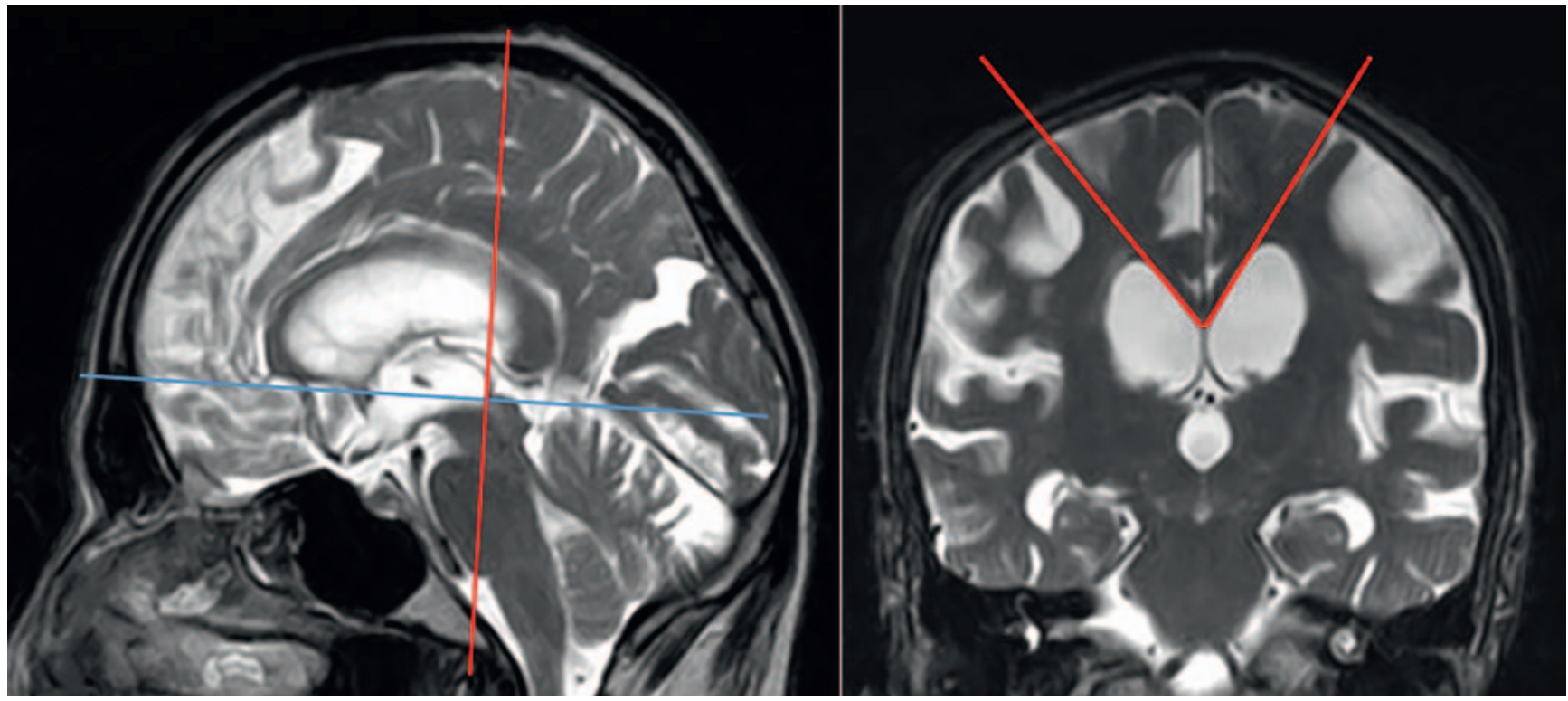

- Fig. 2 Correct measurement of the CC angle is important. A sagittal and paracoronal T2-weighted sequence is used in this case: The CC angle is measured perpendicular to the AC-PC line (blue) at the level of the PC (red) with a result of $78^{\circ}$. AC: anterior commissure, $\mathrm{PC}$ : posterior commissure.

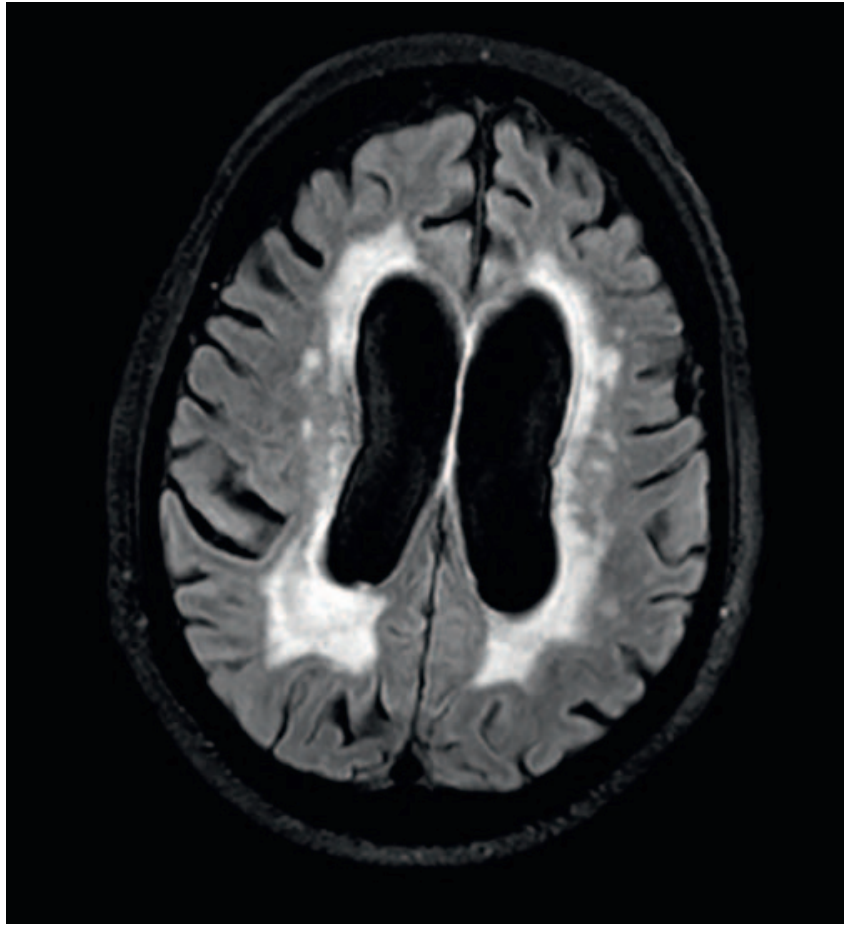

- Fig. 3 Transverse FLAIR sequence of a patient with NPH and typical pronounced microangiopathic changes.

these diseases are to be differentiated clinically from NPH. However, degenerative diseases in particular are problematic since they can present in a similar manner in the initial stages [10]. Microangiopathy and Alzheimer's dementia play a special role here since there is a causal relationship with NPH as described above. Therefore, the clinical as well as radiological features of both diseases are frequently seen and often cannot be reliably differenti- ated from one another. These uncertainties can result in $\mathrm{NPH}$ being underdiagnosed since other diseases seem more obvious.

In the case of hydrocephalus, a differentiation must be made between occlusive and communicating hydrocephalus.

\section{Hydrocephalus}

$\mathrm{NPH}$ is typically classified as primary or secondary. Common causes of secondary NPH include subarachnoid hemorrhage and meningitis, which can often already be suspected based on corresponding symptoms and medical history. Meningeosis carcinomatosa can also cause non-occlusive hydrocephalus but it often progresses more quickly so that it presents with headache and reduced vigilance, i. e., the symptoms of acute hydrocephalus. An increase in FLAIR signal intensity and contrast enhancement in the arachnoid spaces are indications of meningitis and meningeosis on MRI, with the changes seen in meningeosis often being located in the basal cisterns and the cranial nerves. NPH must be differentiated from occlusive hydrocephalus. It can be located on any level of the ventricular system and can be caused by tumors, colloid cysts, displacement of brain tissue, etc. In adults with slowly progressing hydrocephalus, aqueduct stenosis can become noticeable. An enlarged third ventricle and narrow fourth ventricle are typical. A pressure gradient over the third ventricle can be seen on thin-slice sagittal T2-weighted images. In addition, the patency of the aqueduct can be evaluated here ( $\triangleright$ Fig. 4). However, the flow voids are often so significant that evaluation is difficult (see CSF flow visualization).

Infratentorial intracisternal obstructive hydrocephalus can have the same clinical picture as NPH due to its slow development, but it is caused by an occlusion mechanism and must therefore be pathophysiologically differentiated from NPH. Infratentorial intracisternal obstructive hydrocephalus is characterized by a pressure gradient between the ventricular system and external CSF spaces, which is not seen in NPH. The site of occlusion is not 


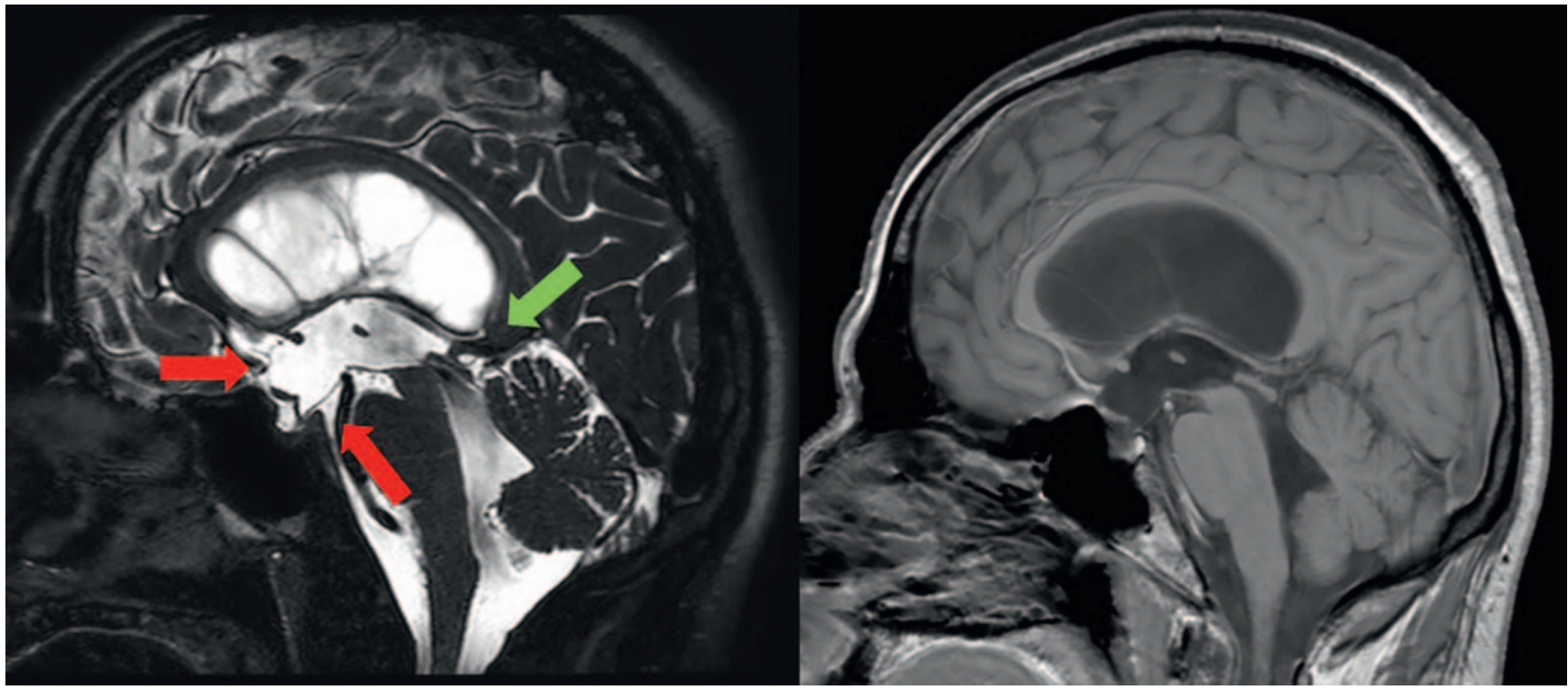

- Fig. 4 Patient with infratentorial intracisternal obstructive hydrocephalus: The patient presented with a gait disturbance with suspicion of NPH. The left image is a sagittal T2 sequence showing a pronounced flow void in the aqueduct that limits visibility of the aqueduct. the sagittal T1 sequence provides better visibility of the aqueduct. The lowering of the floor of the third ventricle and the bulging of the lamina terminalis indicate a pressure gradient between the internal and external CSF spaces. The patient underwent ventriculocisternostomy resulting in rapid improvement of symptoms.

visible. It is suspected that it is between the cisterna magna and the prepontine cisterns. Infratentorial intracisternal obstructive hydrocephalus accounts for approximately $10 \%$ of patients with chronic hydrocephalus. These patients are younger than NPH patients ( $\triangleright$ Fig. 5) ( $\triangleright$ Table 1 ).

\section{Parkinson's disease}

Among the degenerative diseases, Parkinson's disease is the most important differential diagnosis to NPH due to its frequency and clinical similarity in the early phase. NPH patients can exhibit bradykinesia, rigidity, and postural instability, but the tremor typically seen in Parkinson's disease is absent. These symptoms can improve after a shunt is placed [30, 31]. The only finding indicating Parkinson's disease on imaging is the absence of the swallow tail sign with a positive predictive value of $69 \%$. In healthy patients, SWI-weighted sequences show nigrosome- 1 of the substantia nigra as a band with increased signal intensity while a band with decreased signal intensity is seen in Parkinson's patients [32].

\section{Microangiopathy}

Confluent white matter lesions are typically seen in NPH patients ( $\triangleright$ Fig.3). These are due to demyelination of the white matter caused by microangiopathy. Moreover, microangiopathy is manifested in the form of lacunar infarcts in the basal ganglia and pontine lesions. Interstitial CSF absorption as typically seen in hydrocephalus with elevated CSF pressure and as can be confused with microangiopathy is not seen in NPH. Since microangiopathy is also associated with a reduction of brain volume and enlargement of the ventricular system, it can be impossible on imaging to rule out the additional presence of NPH when the typical imaging findings (DESH) are not present. The manifestations of both diseases can also be clinically similar and include subcortical frontal dementia and a gait disturbance [33].

\section{Alzheimer's disease}

$\mathrm{NPH}$ is less commonly associated with Alzheimer's disease than with microangiopathy. Particularly in the initial stage, the clinical picture is often less specific so that differentiation can be difficult. Therefore, a cohort study showed that Alzheimer's dementia was ultimately diagnosed in approximately one third (36\%) of patients with initial suspicion of NPH (after an average of 4.8 years) [34]. Patients with NPH have beta-amyloid deposits in $40-75 \%$ of cases. However, this does not necessarily mean that Alzheimer's disease is present. People with normal cognitive abilities can also have these deposits but have a higher rate of cerebral atrophy and cognitive decline (26\% vs. $7 \%$ ) over a period of 3 years [35]. Therefore, the development of Alzheimer's disease involves additional mechanisms [36]. There could be a pathophysiological connection with respect to the glymphatic system. However, this is not yet generally recognized (see pathophysiology). The typical imaging signs of late-stage Alzheimer's disease are a temporomesial and a parietal volume reduction. The mesial temporal atrophy (MTA) score, which is based on the width of the choroidal fissure and the temporal horn and the height of the hippocampus can be used to quantify temporal volume reduction ( $\triangleright$ Fig. 6). In addition, there can be widening of the parietal sulci of the cerebral cortex in Alzheimer's disease. Hippocampal sclerosis, which can be seen in temporal lobe epilepsy and occurs bilaterally in up to $10 \%$ of cases, must be differentiated from Alzheimer's disease. Findings of hippocampal sclerosis include reduced volume, increased signal intensity, and an abnormal internal structure: Loss of digitations and loss of the three-layer structure ( $\triangleright$ Fig. 7 ). These regions are not specifically enlarged in NPH [19]. 

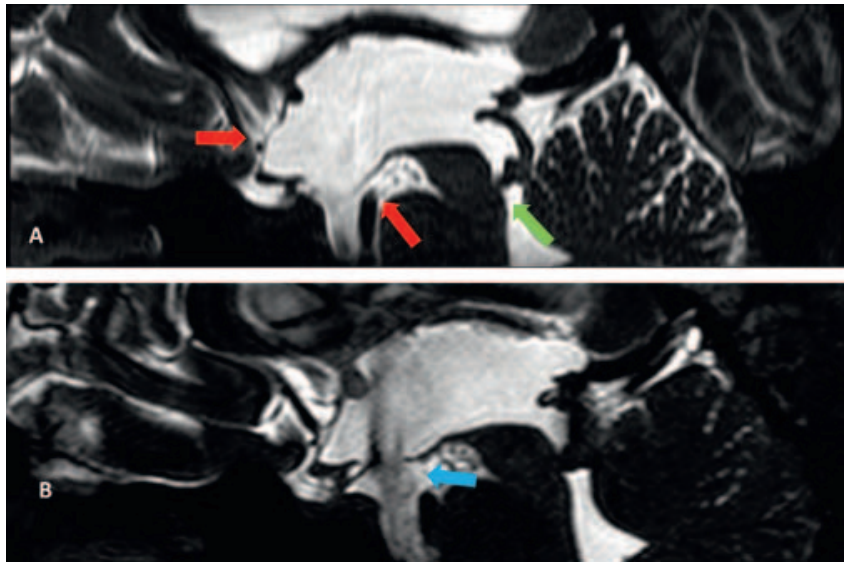

- Fig. 5 Patient with stenosis of the aqueduct with a typical location at the outlet (green arrow). No flow void as a sign of CSF flow but bulging of the lamina terminals and lowering of the floor of the third ventricle as signs of a pressure gradient between the third ventricle and external CSF system are seen in the sagittal T2-weighted sequence shown in the top image $\mathbf{A}$. A flow void over the floor of the third ventricle can been seen after ventriculocisternostomy in the bottom image $\mathbf{B}$. As a sign of the effectiveness, the third ventricle is no longer dilated.

\section{Additional degenerative diseases}

Other degenerative diseases, like progressive supranuclear palsy (PSP), multiple system atrophy (MSA), and frontotemporal dementia (FTLD), are less clinically relevant with respect to differential diagnosis due to their rarity and the ability to differentiate them from NPH. The most important imaging findings for differential diagnosis are summarized in $>$ Table 2.

\section{Treatment}

$\mathrm{NPH}$ is treated by placing a ventriculoperitoneal shunt. The removal of CSF makes the CSF compartment compressible and also allows absorption of the water hammer pulse. Infratentorial intracisternal obstructive hydrocephalus, which must be differentiated from $\mathrm{NPH}$, is treated by ventriculocisternostomy with the advantage that no foreign material needs to be implanted. Repeated removal of CSF via lumbar puncture is only considered as an exception in multimorbid patients with a surgical risk that is too high. The shunt is implanted via a frontal (less commonly temporal-occipital) entry point. Lumboperitoneal shunts are the exception in Europe but are often used in Japan.

Hydrostatic valves are now used. With significantly lower rates of overdrainage, they are significantly better than older valves. Less CSF is drained when the patient is standing but these valves must be implanted at an angle of $+/-20^{\circ}$ with respect to the longitudinal axis of the body to function properly. The total complication rate after shunt placement is currently between $8 \%$ and $28 \%$ in large multicenter studies. Overdrainage is the most common complication, which presents as clinical worsening and headache and manifests on imaging as hygroma or subdural hematoma and narrowing of the ventricles or slit ventricles (5-15\%). Intracerebral hemorrhage is very rare $(0.2 \%)$. Shunt infection is slightly more

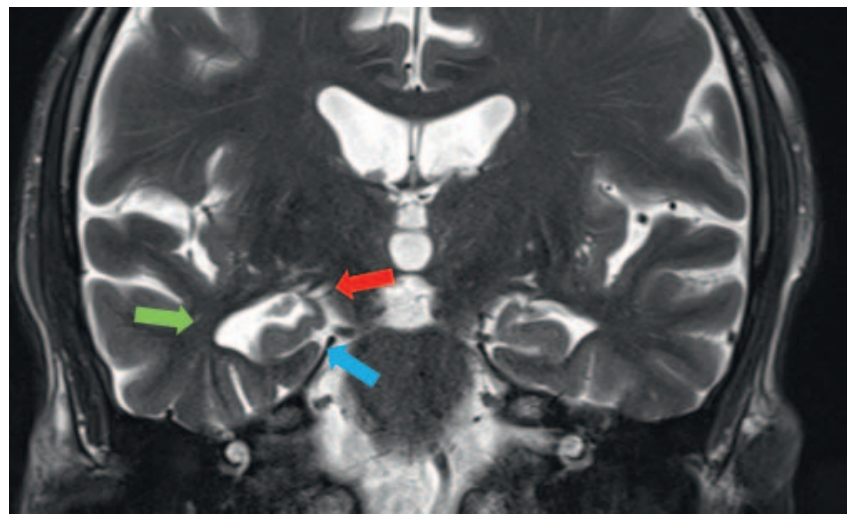

- Fig. 6 60-year-old patient with Alzheimer's-type dementia. The paracoronal T2-weighted sequence shows bilateral (more pronounced on the right) widening of the temporal horn (green arrow) and the choroidal fissure (red arrow) and moderate decrease in the height of the hippocampus (blue arrow) corresponding to an MTA score of 2 .

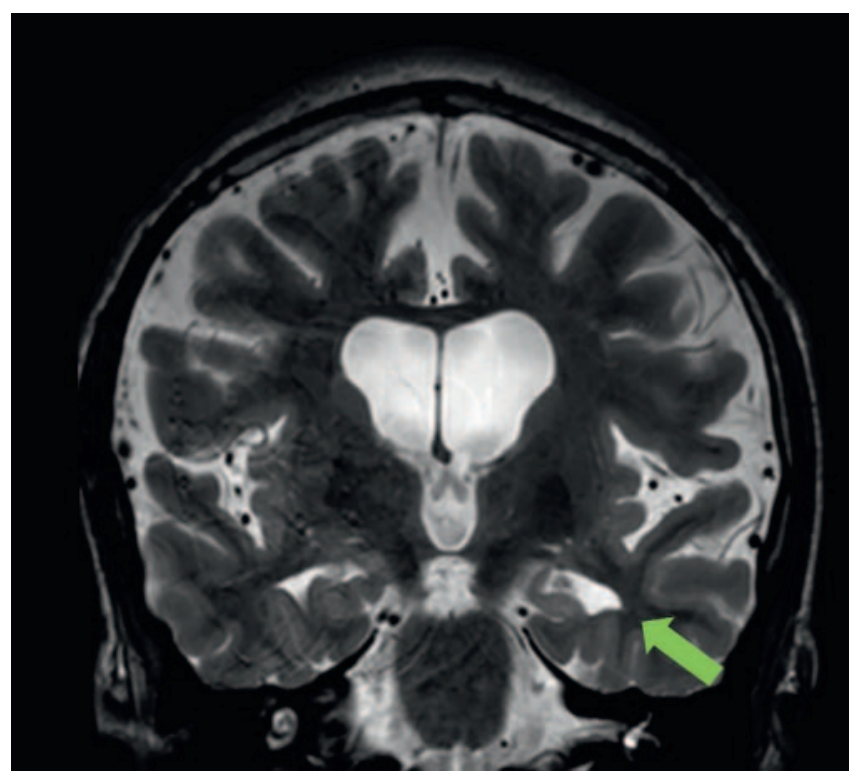

- Fig. 7 Patient with known epilepsy and hippocampal sclerosis (left). The paracoronal T2 sequence shows widening of the left temporal horn compared to the right one (green arrow). The hippocampus is flattened, there are no visible digitations, and there is an increase in signal intensity.

common (3.5\%) ( $\triangleright$ Fig. 8). The shunt revision rate is $13 \%$. The complication rate has decreased significantly in recent years (previously up to $38 \%$ ) with the rate of shunt infection and shunt revision decreasing less significantly than the rate of hemorrhage and overdrainage.

In the case of corresponding selection, clinical improvement can be achieved after shunt placement in 70-90\% of patients. However, after approximately one year, symptoms often increase again so that the success rate after 5 years decreases to approximately $40 \%$. This worsening is counteracted by reducing the opening pressure of the shunt so that more CSF is drained. Improvement can often be achieved again in this way. However, the 


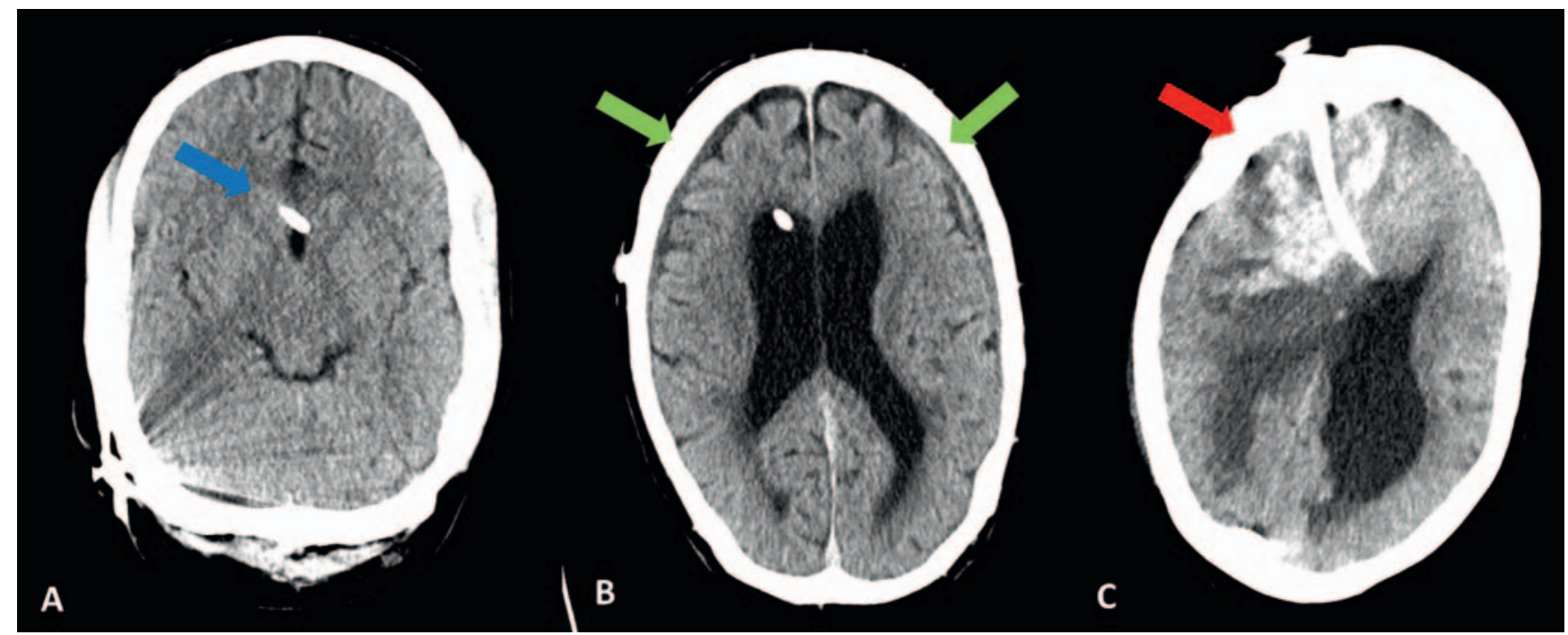

- Fig. 8 Transverse CT images of patients with NPH and complications after shunt placement. Image $\mathbf{A}$ shows the tip of the shunt (blue arrow). The lateral ventricles are completely collapsed, i. e., slit ventricles, as a sign of overdrainage. The width of the ventricular system in image $\mathbf{B}$ is normal. Small subdural hematomas (left bigger than right) are seen as a sign of overdrainage (green arrows). Image $\mathbf{C}$ shows a very rare but serious complication, i. e., significant bleeding after shunt placement (red arrow).

- Table 2 Typical imaging findings of differential diagnoses for NPH.

\begin{tabular}{|c|c|}
\hline clinical diagnosis & MR finding \\
\hline microangiopathy & $\begin{array}{l}\text { leukoaraiosis of white matter, basal } \\
\text { ganglia, and pontine }\end{array}$ \\
\hline Alzheimer's disease & $\begin{array}{l}\text { volume reduction, mesial temporal (MTA } \\
\text { score) and parietal }\end{array}$ \\
\hline Parkinson's disease & swallow tail sign on SWI \\
\hline $\begin{array}{l}\text { progressive } \\
\text { supranuclear palsy }\end{array}$ & $\begin{array}{l}\text { mesencephalic volume reduction, } \\
\text { hummingbird sign, Micky Mouse sign }\end{array}$ \\
\hline $\begin{array}{l}\text { multiple system } \\
\text { atrophy }\end{array}$ & $\begin{array}{l}\text { pontocerebellar volume reduction } \\
\text { "Hot cross bun" sign } \\
\text { increase in signal intensity in the middle } \\
\text { cerebellar peduncle } \\
\text { "Putaminal rim sign" }\end{array}$ \\
\hline $\begin{array}{l}\text { frontotemporal } \\
\text { dementia }\end{array}$ & frontal and temporal volume reduction \\
\hline
\end{tabular}

effect is not lasting. This decrease in treatment success is explained among other things by the progression of the underlying microangiopathy or comorbidities and the fact that the NPH treatment is ultimately only symptomatic. An early treatment start is important for success since the chance for improvement decreases with disease progression. The symptom with the best response to treatment is gait disturbance. It improves in approximately two-thirds of patients. Incontinence can also be positively impacted in many patients. However, the symptoms of dementia are significantly more difficult to treat ( $18 \%$ and $21 \%$ ). This is viewed as an indication that the cause is primarily the simultaneous presence of microangiopathy or a degenerative disease
[37]. The main predictors of the success of shunt placement are the severity of the initial symptoms, the duration of symptoms, the presence of comorbidities, and a typical imaging finding with DESH [38-44].

\section{Summary}

$\mathrm{NPH}$ is an important differential diagnosis in older patients with a gait disturbance and a dementia syndrome. The differential diagnosis is complicated by the often simultaneous presence of microangiopathy and Alzheimer's dementia. NPH comprises a majority of cases of treatable dementia. The primary radiological signs of $\mathrm{NPH}$ are DESH and a small CC angle. Important differential diagnoses are infratentorial intracisternal obstructive hydrocephalus and aqueduct stenosis.

Proper selection of patients is an important requirement for the lasting success of a shunt. Today, the complication rates for shunt placement are low. In particular, gait disturbance can be treated very effectively with shunt placement.

Conflict of Interest

The authors declare that they have no conflict of interest.

References

[1] Hakim S, Adams RD. The special clinical problem of symptomatic hydrocephalus with normal cerebrospinal fluid pressure. Observations on cerebrospinal fluid hydrodynamics. J Neurol Sci 1965; 2: 307-327

[2] Adams RD, Fisher CM, Hakim S et al. Symptomatic Occult Hydrocephalus with "Normal" Cerebrospinal-Fluid Pressure. A Treatable Syndrome. N Engl J Med 1965; 273: 117-126 
[3] Jaraj D, Rabiei K, Marlow T et al. Prevalence of idiopathic normal-pressure hydrocephalus. Neurology 2014; 82: 1449-1454

[4] Jaraj D, Agerskov S, Rabiei K et al. Vascular factors in suspected normal pressure hydrocephalus: A population-based study. Neurology 2016; 86: 592-599

[5] Picascia M, Minafra B, Zangaglia R et al. Spectrum of cognitive disorders in idiopathic normal pressure hydrocephalus. Funct Neuro 2016; 31: 143-147. doi:10.11138/fneur/2016.31.3.143

[6] Cabral D, Beach TG, Vedders L et al. Frequency of Alzheimer's disease pathology at autopsy in patients with clinical normal pressure hydrocephalus. Alzheimers Dement 2011; 7: 509-513. doi:10.1016/j. jalz.2010.12.008. Epub 2011 Jul 1

[7] Rendtorff R, Novak A, Tunn R. Normal Pressure Hydrocephalus as Cause of Urinary Incontinence - A Shunt for Incontinence. Geburtshilfe Frauenheilkd 2012; 72: 1130-1131

[8] Kuriyama N, Miyajima M, Nakajima M et al. Nationwide hospital-based survey of idiopathic normal pressure hydrocephalus in Japan: Epidemiological and clinical characteristics. Brain Behav 2017; 7: e00635 [published 2017 Jan 27]

[9] Kehler U, Hattingen E. Normal pressure Hydrocephalus. Radiologie up2date 2017; 17: 119-136

[10] Oliveira LM, Nitrini R, Román GC. Normal-pressure hydrocephalus: A critical review. [published correction appears in Dement Neuropsychol. 2019 Jul-Sep;13(3):361] Dement Neuropsychol 2019; 13: 133-143

[11] Bradley WG Jr, Whittemore AR, Watanabe AS et al. Association of deep white matter infarction with chronic communicating hydrocephalus: implications regarding the possible origin of normal-pressure hydrocephalus. AJNR Am J Neuroradiol 1991; 12: 31-39

[12] Rasmussen MK, Mestre H, Nedergaard M. The glymphatic pathway in neurological disorders. Lancet Neurol 2018; 17: 1016-1024

[13] Paulus W, Krauss JK (geteilte Erstautorenschaft). S1-Leitlinie Normaldruckhydrozephalus. In: Deutsche Gesellschaft für Neurologie, Hrsg. Leitlinien für Diagnostik und Therapie in der Neurologie. 2018. Online (abgerufen am 20.06.2020): www.dgn.org/leitlinien

[14] Bradley WG Jr. Magnetic Resonance Imaging of Normal Pressure Hydrocephalus. Semin Ultrasound CT MR 2016; 37: 120-128

[15] Damasceno BP. Neuroimaging in normal pressure hydrocephalus. Dement Neuropsychol 2015; 9: 350-355

[16] Evans WA. An encephalographic ratio for estimating ventricular enlargement and cerebral atrophy. Arch Neurol Psychiat 1942; 47: 931-937

[17] Toma AK, Holl E, Kitchen ND et al. Evans' index revisited: the need for an alternative in normal pressure hydrocephalus. Neurosurgery 2011; 68: 939-944

[18] Miskin N, Patel H, Franceschi AM et al. Diagnosis of Normal-Pressure Hydrocephalus: Use of Traditional Measures in the Era of Volumetric MR Imaging. Radiology 2017; 285: 197-205

[19] Takagi K, Watahiki R, Machida T et al. Reliability and Interobserver Variability of Evans' Index and Disproportionately Enlarged Subarachnoid Space Hydrocephalus as Diagnostic Criteria for Idiopathic Normal Pressure Hydrocephalus. Asian ] Neurosurg 2020; 15: 107-112

[20] Sjaastad O, Nordvik A. The corpus callosal angle in the diagnosis of cerebral ventricular enlargement. Acta Neurol Scand 1973; 49: 396-406

[21] Ishii K, Kanda T, Harada A et al. Clinical impact of the callosal angle in the diagnosis of idiopathic normal pressure hydrocephalus. Eur Radiol 2008; 18: $2678-2683$

[22] Krauss JK, Regel JP, Vach W et al. White matter lesions in patients with idiopathic normal pressure hydrocephalus and in an age-matched control group: a comparative study. Neurosurgery 1997; 40: 491-495
[23] Inatomi Y, Yonehara T, Hashimoto Y et al. Correlation between ventricular enlargement and white matter changes. J Neurol Sci 2008; 269: 12-17

[24] Krauss JK, Regel JP, Vach W et al. Flow void of cerebrospinal fluid in idiopathic normal pressure hydrocephalus of the elderly: can it predict outcome after shunting? Neurosurgery 1997; 40: 67-73

[25] Yamada S, Kelly E. Cerebrospinal Fluid Dynamics and the Pathophysiology of Hydrocephalus: New Concepts. Semin Ultrasound CT MR 2016; 37 : 84-91

[26] Shanks ], Markenroth Bloch K, Laurell K et al. Aqueductal CSF Stroke Volume Is Increased in Patients with Idiopathic Normal Pressure Hydrocephalus and Decreases after Shunt Surgery. AJNR Am J Neuroradio 2019; 40: 453-459. doi:10.3174/ajnr.A5972 [Epub 2019 Feb 21]

[27] Bradley WG Jr, Scalzo D, Queralt J et al. Normal-pressure hydrocephalus: evaluation with cerebrospinal fluid flow measurements at MR imaging. Radiology 1996; 198: 523-529. doi:10.1148/radiology.198.2.8596861

[28] Ringstad G, Emblem KE, Geier O et al. Aqueductal Stroke Volume: Comparisons with Intracranial Pressure Scores in Idiopathic Normal Pressure Hydrocephalus. AJNR Am J Neuroradiol 2015; 36: 1623-1630. doi:10.3174/ajnr.A4340 [Epub 2015 May 14]

[29] Bradley WG Jr. CSF Flow in the Brain in the Context of Normal Pressure Hydrocephalus. AJNR Am J Neuroradiol 2015; 36: 831-838

[30] Kiefer M, Unterberg A. The differential diagnosis and treatment of normal-pressure hydrocephalus. Dtsch Arztebl Int 2012; 109: 15-26

[31] Molde K, Söderström L, Laurell K. Parkinsonian symptoms in norma pressure hydrocephalus: a population-based study. J Neurol 2017; 264: 2141-2148. doi:10.1007/s00415-017-8598-5 [Epub 2017 Sep 6]

[32] Schwarz ST, Afzal M, Morgan PS et al. The "swallow tail" appearance of the healthy nigrosome - a new accurate test of Parkinson's disease: a case-control and retrospective cross-sectional MRI study at 3T. PLoS One 2014; 9: e93814

[33] Tullberg M, Hultin L, Ekholm S et al. White matter changes in normal pressure hydrocephalus and Binswanger disease: specificity, predictive value and correlations to axonal degeneration and demyelination. Acta Neurol Scand 2002; 105: 417-426

[34] Koivisto AM, Kurki MI, Alafuzoff I et al. High Risk of Dementia in Ventric ular Enlargement with Normal Pressure Hydrocephalus Related Symptoms1. J Alzheimers Dis 2016; 52: 497-507

[35] Mormino EC, Papp KV. Amyloid Accumulation and Cognitive Decline in Clinically Normal Older Individuals: Implications for Aging and Early Alzheimer's Disease. J Alzheimers Dis 2018; 64: S633-S646

[36] Jagust $W$. Is amyloid- $\beta$ harmful to the brain? Insights from human imaging studies. Brain 2016; 139: 23-30

[37] Malm J, Graff-Radford NR, Ishikawa M et al. Influence of comorbidities in idiopathic normal pressure hydrocephalus - research and clinical care. A report of the ISHCSF task force on comorbidities in INPH. Fluids Barriers CNS 2013; 10: 22

[38] Yamada S, Ishikawa M, Yamaguchi M et al. Longitudinal morphological changes during recovery from brain deformation due to idiopathic normal pressure hydrocephalus after ventriculoperitoneal shunt surgery. Sci Rep 2019; 9: 17318

[39] Toma AK, Papadopoulos MC, Stapleton S et al. Systematic review of the outcome of shunt surgery in idiopathic normal-pressure hydrocephalus. Acta Neurochir (Wien) 2013; 155: 1977-1980

[40] Craven CL, Toma AK, Mostafa T et al. The predictive value of DESH for shunt responsiveness in idiopathic normal pressure hydrocephalus. J Clin Neurosci 2016; 34: 294-298

[41] Bugalho P, Alves L. Normal-pressure hydrocephalus: white matter lesions correlate negatively with gait improvement after lumbar puncture. Clin Neurol Neurosurg 2007; 109: 774-778

[42] Klinge P, Hellström P, Tans J et al. One-year outcome in the European multicentre study on iNPH. Acta Neurol Scand 2012; 126: 145-153 
[43] Wu EM, El Ahmadieh TY, Kafka B et al. Ventriculoperitoneal Shunt Outcomes of Normal Pressure Hydrocephalus: A Case Series of 116 Patients. Cureus 2019; 11: e4170

[44] Halperin JJ, Kurlan R, Schwalb JM et al. Practice guideline: Idiopathic normal pressure hydrocephalus: Response to shunting and predictors of response: Report of the Guideline Development, Dissemination, and
Implementation Subcommittee of the American Academy of Neurology. [published correction appears in Neurology. 2016 Feb 23;86(8):793] Neurology 2015; 85: 2063-2071

[45] Virhammar J, Laurell K, Cesarini KG et al. Preoperative prognostic value of MRI findings in 108 patients with idiopathic normal pressure hydrocephalus. AJNR Am J Neuroradiol 2014; 35: 2311-2318 